\title{
Preclinical evaluation of effects of aqueous extract of tetrapleura tetraptera fruits on induced diabetic ulcers on rabbits
}

\author{
${ }^{1}$ Hilary E. Otimanam, ${ }^{2}$ Adedayo Tologhonse, ${ }^{2}$ Ngozi Onwuka, ${ }^{2}$ Anwana-abasi Udo and \\ ${ }^{2}$ Nkechi Onyeuka \\ ${ }^{1}$ Department of Clinical Pharmacology/Therapeutics, Faculty of Clinical Sciences, University \\ of Uyo, Nigeria. \\ ${ }^{2}$ Department of Pharmacology/Toxicology, Faculty of Pharmacy, University of Uyo, Nigeria.
}

Received: 11-11-2021 / Revised Accepted: 21-12-2021 / Published: 02-01-2022

\begin{abstract}
Diabetes and its complications especially diabetic foot ulcer (DFU) is a chronic disease that has plagued humanity for centuries. Despite being one of the oldest diseases composite therapy has eluded the medical world till date. Tetrapleura tetraptera fruits, were crushed and divided into two equal parts for boiling and burning and soaked in equal volume of sterile water. Analysis of the extract confirmed the presence of alkaloids, flavonoids, saponins and tannins. Twenty-four mature adult rabbits were used for this research. After 12 hours fast, they were injected with freshly prepared alloxan monohydrate, $120 \mathrm{mg} / \mathrm{kg}$ body weight intraperitoneally. They were divided into three groups of eight rabbits $(n=8)$. Wound excision measuring about $2.2 \mathrm{~cm}$ was created on the back of the rabbits. The extract and honey were then used to dress the wounds, group I dressed with the extract, group II dressed with honey as standard; group III received no treatment. Wound contraction was measured every two days until complete epithelialization which signified complete closure. Aqueous extract of T. tetraptera fruits showed significant wound healingrate $(\mathrm{P}<0.05)$ and reduced epithelialization time within 16 days. Tetrapleura tetraptera aqueous extract showed great promise and potential of the plant in treating stubborn wounds.
\end{abstract}

Keywords: Excision, Phytochemicals, Tetrapleura tetraptera, Re-epithelilization, Alloxa monohydrate

\section{INTRODUCTION}

Diabetic foot ulcer is considered one of the most significant complications of diabetes, representing a major worldwide medical, social and economic problem that greatly affects patient quality of life.
The risk for a patient with diabetes to develop foot ulcer is close to $25 \%$ [1] leading frequently to disablement and leg amputation [2,3]. It has been estimated that every 30 seconds the lower limb is amputated somewhere in the world because of diabetes [4].

Address for Correspondence: Hilary E. Otimanam, Department of Clinical Pharmacology/Therapeutics, Faculty of Clinical Sciences, University of Uyo, Nigeria.; E-mail: drotimanam@yahoo.com

How to Cite this Article: Hilary E. Otimanam, Adedayo Tologhonse, Ngozi Onwuka, Anwana-abasi Udo and Nkechi Onyeuka. Preclinical evaluation of effects of aqueous extract of tetrapleura tetraptera fruits on induced diabetic ulcers on rabbits. World J Pharm Sci 2022; 10(01): 1-9;

https://doi.org/10.54037/WJPS.2022.100101

Copyright: 2022@ The Author(s). This is an open access article distributed under the terms of the Creative Commons AttributionNonCommercial-ShareAlike 4.0 International License (CC BY-NC-SA), which allows re-users to distribute, remix, adapt, and build upon the material in any medium or format for noncommercial purposes only, and only so long as attribution is given to the creator. If you remix, adapt, or build upon the material, you must license the modified material under identical terms. 
Diabetes is long regarded as one of the most prevalent chronic diseases in the United States; diabetes is also a leading cause of disability and the seventh leading cause of death. Less discussed is one of the most common complications of diabetes: diabetic foot ulcers. If not properly treated with standard and adjunctive care, these chronic wound can lead to permanent disability and premature death [5]. Annual risk of developing a DFU may be as high as $4 \%$ and the lifetime risk may be as high as $34 \%$ [6].

Without prompt intervention and proper treatment, DFUs will not heal, can cause soft tissue and/or bone infection and may eventually require amputation of the affected limb or appendage. Unfortunately, this is not uncommon. 1 in 6 patients with a DFU will undergo an amputation making DFUs the leading cause of non-traumatic amputations in the country [7]. Given the prevalence and risks associated with DFUs, it is imperative that clinicians understand, having access to, and use the best available science for the treatment of these hard-to-heal wounds.

Plants have the immense potential for the management and treatment of wounds. A large number of plants are used by tribal and folklore in many countries for the treatment of wounds. The natural agents induce healing and regeneration of lost tissue by multiple mechanisms. These phytochemicals are not only cheap and affordable but also safe. The presence of various lifesustaining constituents in plants has urged scientist to examine these plants with a view to determine potential wound healing properties [8].

Many phytopharmaceutical laboratories are now concentrating their efforts to identify the action constituents and mode of various medicinal plants [9]. These constituents include various chemical families like alkaloids, essential oils, flavonoids, tannins, terponoids, saponins and phenolic compounds [10].

A number of reports concerning the antibacterial, anti-inflammatory and wound healing activity of various plants have appeared in the literature, but the vast majority has yet to be explored. Various pharmacological reports are available on plants employing different wound healing models for the validation of their traditional claims and development of safe and effective globally accepted herbal drugs for wound [11].

Screening of herbal extracts has been of great interest to the scientists for the discovery of new effective drugs. A number of reports concerning the antimicrobial, anti-inflammatory and wound healing activity of various plants have appeared [9-
12], but the vast majority has yet to be explored. Various pharmacological reports are available plants, employing different wound healing models and its underlying molecular mechanism for the validation of their traditional claims and development of safe and effective and globally accepted herbal drugs for wounds healing models for their validation of their traditional claims and effectiveness are globally accepted.

Tetrapleura tetraptera (family, minosaceae) is a single stemmed, robust, perennial tree with dark green leaves and woody base spreading branches. Various preparations of the plant are known to be used in folklore medicine for treating human ailments including cardiovascular medicine for treating human ailments including cardiovascular disorders such as hypertension, asthma, diabetes mellitus, epilepsy and schistosomiasis [13]. The plant is also frequently used in Tropical African traditional medicine for the management of several women's diseases such as breast cancers, uterine cancers as well as inflammatory conditions [14]. The fruits extract of the plant has shown to possess hypercholestocaemic effects in rats [15], as well as alterations of various parameters in rabbits [16]. Cardiovascular and neuromuscular actions or scopeletin isolated from $\mathrm{T}$. tetraptera were also described. The pods and/or fruits have been shown to have antibacterial effects against Bacillus species, Enterococcus taccalis, Escherichia coli, Klebsiella pneumonice, Staphylococcus aureus, Salmonella typhi, Pseudomonas auriginosa and Shigella [17]. The documented biological and pharmacological activities are foundto be molluscicidal, carciovascular, neuromuscular, hypotensive, anticonvulsive, trypanosomicidal, shistosomiasis control, antiulcerative, cytotoxic, anti-inflammatory, hypoglycaemic, antimicrobial, emulsifying, important at birth control, of food value and control of intestinal parasites [18]. Elizzi et al reported that the stem bark of Tetrapleura tetraptera showed an inhibiting effect on luteinizing hormone released by anterior pituitary gland. T. tetraptera has been shown to cause elevation in Serum Aspartate (AST) and amino transferase (AST) alteration of various metabolites and did not induce any marked pathological lesions in the liver [19]. The anticonvulsant and analgesic effect of T. tetraptera in mic have been reported [20]. The aqueous extract of $\mathrm{T}$. tetraptera fruits have been shown to possess anti-inflammatory and hypoglycaemic properties [21]. The fruit is used to prepare food for mothers from the day of birth to prevent postpartum haemorrhage [22]. The fruit is also used as dietary supplement rich in vitamins in southern and eastern Nigeria [23]. The allelopathic potential of $\mathrm{T}$. tetraptera has led to its integration into agroforestry [24]. Many researchers have reported to use of $\mathrm{T}$. tetraptera aqueous stem-bark 
on treatment of wounds [25] but very few researchers have ever reported the use of $T$. tetraptera fruits aqueous extract on wound dressing treatment. This may be due to thick and deep brown nature of the crushed boiled (decoction) which may head special technique to separate the thick mixture. T. tetraptera fruits have immense potential for the management and treatment of wounds. Large number of plants have been used by tribal and folklore in many countries for treatment of wounds and burns. These natural agents induce healing and regeneration of the lost tissue by multiple mechanisms. These phytomedicines are not only cheap and affordable but are also safe. The presence of various life sustaining constituents in plants have urged scientists to examine tehse plants with a view to determine potential wound healing properties (27). Many phytopharmaceutical laboratories are now concentrating their efforts to identify the active constituents and mode of action of various medicinal plants. These medicinal values of these plants lie in bioactive phytochemical constituents that produce definite physiological action on human body. These constituents include various chemical families like alkaloids, flavonoids, essential oil, saponins, phenols and tannins [28]. Therefore, this research becomes quite imperative in order to harness and demonstrate the potential of Tetrapleura tetraptera in wound healing.

\section{MATERIALS AND METHODS}

The dried fruits of Tetrapleura tetraptera were collected from the wild which is its natural habitat in a forest in Akamkpa, Cross River State, Nigeria. The plant was identified by the principal curator, Department of Pharmacognosy, Faculty of Pharmacy, University of Uyo, Akwa Ibom State, Nigeria and the voucher specimen (A 32(f) Schum and Thorns) were kept at Herbarium of the Faculty of Pharmacy.

The fresh dried fruits of the plants were carefully selected for the study. Afterwards, the fruits were washed with clean water before undergoing drying process under a shade for some days. The fleshy portion of the fruits were carefully separated from the hard-core central portion which contains the seeds by grating using crater to form a paste. The ground fruits were divided into two equal portions of 1 kilogramme each. One portion was boiled with 2 litres of sterile water for 40 minutes while the second portion was heated until it became charred and turned black using a frying pan. It was thereafter dissolved in 2 litres of sterile water. The two preparations were thoroughly mixed, filtered, allowed to stand overnight in an effort to get the fine suspended particles sedimented. The supernatant was carefully decanted out giving a brown colour, while the sediment was discarded. Five hundred $(500 \mathrm{ml})$ of the extract was concentrated using rotary evaporator and a thick paste-like brown crude extract was obtained. The brown crude extract obtained was subjected to phytochemical screening, alkaloids, flavonoids, phenols, saponins and tannins were identified.

Animal Ethics Approval: Animal Ethics Committee (AEC) which regulates and authorizes all use of animals for research, teaching and experimentation subjected to their variable ethical principles and regulatory guidelines was through written proposal for approval for the use of animals. Adequate care, housing and handling were maintained. The animals were treated humanely in accordance with the ethics acts and regulations and all procedures were carried out in accordance with the code of practice for care of and use of animals for scientific purposes.

Animal Handling: Animal of either sex, same age group and approximately of similar weight were employed following acclimatization period of about 2 weeks. They were maintained at a wellventilated animal house under standard controlled conditions of temperature and relative humidity and kept under 12/12 hour light/dark cycles with free access to food and water libitum. The animals were housed individually in clean cages containing paddy husk as bedding.

Induction Protocol of Diabetes Mellitus: All animals were allowed to fast for 12 hours and were injected intraperitaneally with freshly prepared alloxan monohydrate (Sigma Aldrich BVBA, Overijese Belgium) on normal saline in a dose of $120 \mathrm{mg} / \mathrm{kg}$ body weight. Blood glucose levels of these animals were estimated before induction. To reduce the risk of nephrotoxicity and hyperglycaemia, $7 \mathrm{ml} / \mathrm{kg}$ body weight of $0.9 \%$ saline ( $\mathrm{NaCl}$ solution) was given. The animals were given $7 \mathrm{ml}$ of $5 \%$ dextrose solution using orogastric tube immediately after induction to overcome druginduced hypoglycaemia. A rest of 72 hours was allowed during which the animals were allowed to have food and water, diabetes developed after 72 hours. The blood glucose levels were measured using glucometer Fine Test (Life span USA). Blood glucose levels above $200 \mathrm{mg} / \mathrm{dl}$ were considered diabetic and were used for the experiment.

Wound Creation: All surgical interventions were carried out under sterile conditions. The predetermined area for wound infliction on the ear or back of the animal was prepared for surgery by removing hairs with depilatory shaving machine. The animals anesthesized using xylocaine with 
advenaline to infiltrate the area of surgery in order to render the area of the wound infliction painless.

Excision Wound Model on Rabbit Ear: Excision wounds were inflicted on the dorsal surface of one ear on each rabbit about $2.2 \mathrm{~cm}$ in diameter. The depilated ear of the animal as excised to its full thickness of the skin to obtain wound area of 2.2 $\mathrm{cm}$ diameter and $2 \mathrm{~mm}$ depth. Haemostasis was achieved by dabbing the wound with sterile guaze soaked in normal saline. Twenty four rabbits were used for the experiment, and they were divided into three groups of 8 animals each. The respective therapeutic treatment topically were started on respective groups until complete epithelialization starting from the second day of operation. Percentage wound contraction and period of epithelialization were studied.

Evaluation of Wound Healing: All the animals in the three groups got healed but at slightly different rate. The results obtained from these rabbit ear wound model did not give us what we wanted. This was due failure to establish chronic wound infection whereby biofilm infection is suspected to be present. Though this method we were unable to create diabetic ulcers, so we decided to embark on the $2^{\text {nd }}$ method below.

Histopathological Studies: The wound tissues were carefully cut at the edges at 4 th and 7 th weeks interval for hispathological examination. The tissues were completely fixed in $10 \%$ neutral phosphate buffered formation solution. The formalin fixed tissues were dehydrated through graded alcohol series, cleared in xylene and embedded in paraffin wax. Serial sections of 4$7 \mathrm{~mm}$ thickness were cut using microfome. The sections were processed in alcohol-xylene series and stain with haematoxylin and Eosin (H \& E) and observed for histopathological changes under light microscope and photomicrographs were taken.

\section{RESULTS}

This study of how herbal extract of Tetrapleural tetraptera fruit caused increase rate of wound healing contractive and decreased period of epitheliazation in the test group as compared to standard group and control that received pure honey and no treatment respectively (p. 0.05). The study also indicated the healing effect of $T$. tetraptera fruit produced faster rate of wound healing with epitheliazation period of 17 days when compared to those of standard and control which had epithelialization period of 20 and 20 days. The result is shown in table 1 and figure below. Microscopic histological examination attached script.
Microscopic histopathological examination of the sections prepared from the edges of the wounds of herbal extract, standard and control exhibited the following characteristics. The regenerated tissue section of the control group showed densely inflamed connective tissue with chronic inflammatory cells between the collagen fibres showing incomplete wound healing. The tissue sections from that of standard group composed of collagen fibres, fibroblast with round oval nuclei and blood vessels, many thin walled blood vessels were present whereas regenerated tissue section of the herbal extract showed fibrous connective tissue with scattered inflammatory cells and fibroblast. There was a progressive collagenation with few thin walled blood vessels with small lumina, epithelialization of the tissues wall also observed. The herbal extract showed dense fibrous tissue with thick collagen bundles, fibroblast and scattered inflammatory cells. The difference was almost identical to that of normal tissues. The results showed wound healing was faster in herbal extract group as compared to honey.

\section{DISCUSSION}

Phytochemicals are known to possess many wound healing properties. Plants are known to produce phytochemicals to protect themselves against environmental hazards, disease causing microorganisms. Researches demonstrate that phytochemicals products may be useful to protect humans against hemostasis [29]. While current therapeutic agents for treatment of wounds have generally inadequate efficacy, the medicinal plants have been used in medicine since ancient times are well known for their ability to promote wound healing and prevent infection without grave side effects. Thus herbal therapy may be alternative strategy for treatment of wounds [30]. There is an increasing interest in finding herbal extract with wound healing efficacy, although the use of herbal extract for treating wounds is common in traditional medicine. Wound infection resulting from impaired immunity and exposure to poor hygiene is one of the most common encountered and clinically important impediments to wound healing. The injured skin remains vulnerable to invasive microbial infections of all kinds subsequent development of wound sepsis until complete epithelial repairs has occurred [31].

Injuries become infected, because the wound area is an ideal medium for the multiplication of the infecting organism. Topical antimicrobial therapy is one of the most important methods of wound care. The herbal extracts inhibited microbial growth and accelerated wound healing [32]. The enhanced wound healing potency of the extract may be attributed to free radical-scavenging action 
of and the antimicrobial properties of the phytoconstituents present in the extract and the quicker process of wound healing could be a function of either the individual or the synergistic effects of the bioactive molecules. These active constituents promote the process of wound healing by increasing the strength of collagen fibres either by increasing the circulation or by preventing the cell damage or by promoting the DN synthesis [33].

Pronounced effects on fibroblast motility and the cellular proliferation due to mitogenic activity of herbal extract correlate with its wound healing effect being predominantly dermal. During wound repair, fibroblasts migrate from the wound edges to the wound site, proliferate and subsequently produce collagen, the main component in the extracellular matrix. Stimulation of fibroblasts is one mechanism by which herbal extracts might enhance the wound repair process. Although keratinocytes also needs to migrate from the wound edge to provide a provisional matrix for the fibroblasts to migrate on, this might be accelerated secondary to mature dermal matrix. These latter effects on fibroblasts probably are the result of phytoconstituents of herbal extract that may have a growth factor-like activity or have ability to stimulate the early expression of growth factors [34].

The increasing use of traditional medicines and therapies demands more scientifically sound evidence for principles behind therapies and for effectiveness for the medicines. Recent advancements in the analytical and biological sciences, along with innovation in genomic and proteomics can play an important role in the validation of these therapies. Modern therapies requires the targeting of drug directly to the site of interest and to accomplish that goal in systemic treatment. Gene and stem-cell therapy are emerging as a new and promising approach for enhancing treatment of wound healing [35].

\section{Conclusion and Recommendations}

The regenerated tissues were evaluated for the following histological criteria: the extent for regeneration is dermia, the maturation and organization of the epidermal squamous cells, the thickness of granular cells, the degree of tissue formation in wounds and their comparison with that of the standard wound dressing material, control and the extract. In addition, anglogenesis, congestion, edema, epitheliazation, fibroblast, proliferation, intensity and extent of inflammation (cell infiltration) mononuclear and/or polymorphonuclear cells, necrosis, ulceration, neovascularization and the pattern of cottage, depositions iin the dermis were qualitatively evaluated scoring the epidermal or dermal remodeling in diabetic ulcers, the result showed that the extract of $\mathrm{T}$. tetraptera has marked clinical effects on wound healing than honey which was used as standard wound dressing material and control which nothing was applied.

The frustration met in many scientific research work in finding potent cost effective wound solution by medical scientists despite the amount of billions of dollars spent on the research has forced them to turn to natural products in finding effective wound dressing material. This interest in things natural has led to the production of maggot and other advanced techniques in an effort to overcome difficulty in finding effective wound dressing material. Increasing interest in finding herbal extracts with healing efficacy the use of such extract is very common in traditional medicine.

The increasing use of traditional medicines and therapies demands more scientifically sound evidence for the principles behind the therapies and for effectiveness of medicines. Recent advancements in the analytical and biological sciences have given birth to this innovation which is very essential in validation of these therapies.

In any wound research, the choice of animals can be difficult, since its ability to represent human would healing must be coupled with its practicality. Usually, the rat, mouse, rabbit and guinea pig wound models are very common, swine skin is the most similar to humans and has been shown to be an excellent tool to evaluate wound healing therapies.

\section{Acknowledgement}

The authors are grateful to Tertiary Education trust Fund/Institutional Based Research (TETfund/IBR), Abuja for the financial support to conduct this research. 
Effect of Aqueous Extract of Tetrapleura tetraptera fruits on Excision Wounds on Diabetic Rats (MEAN)
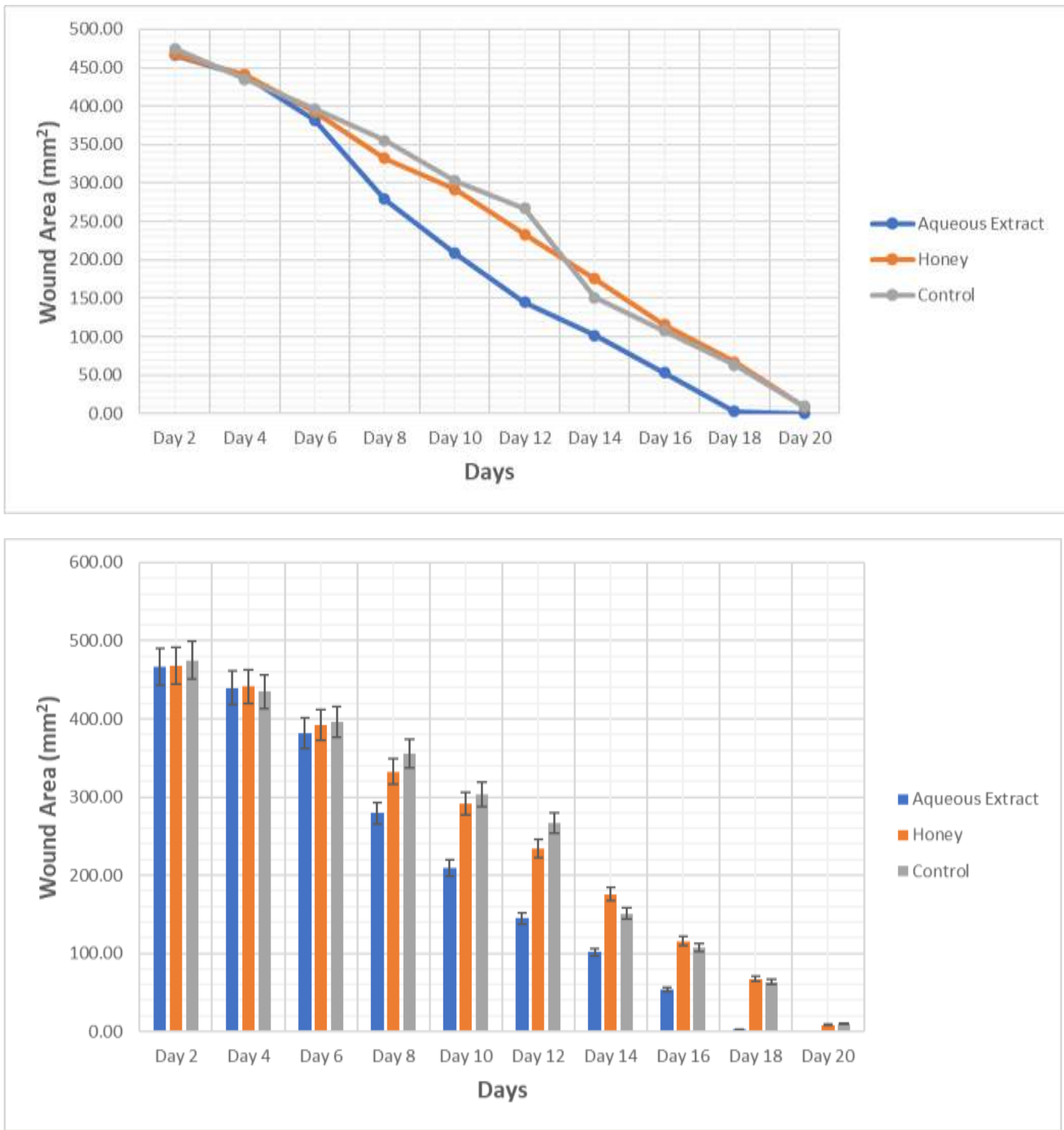
Effect of Aqueous Extract of Tetrapleura tetraptera fruits on Excision Wounds on Diabetic Rats (STDEV)
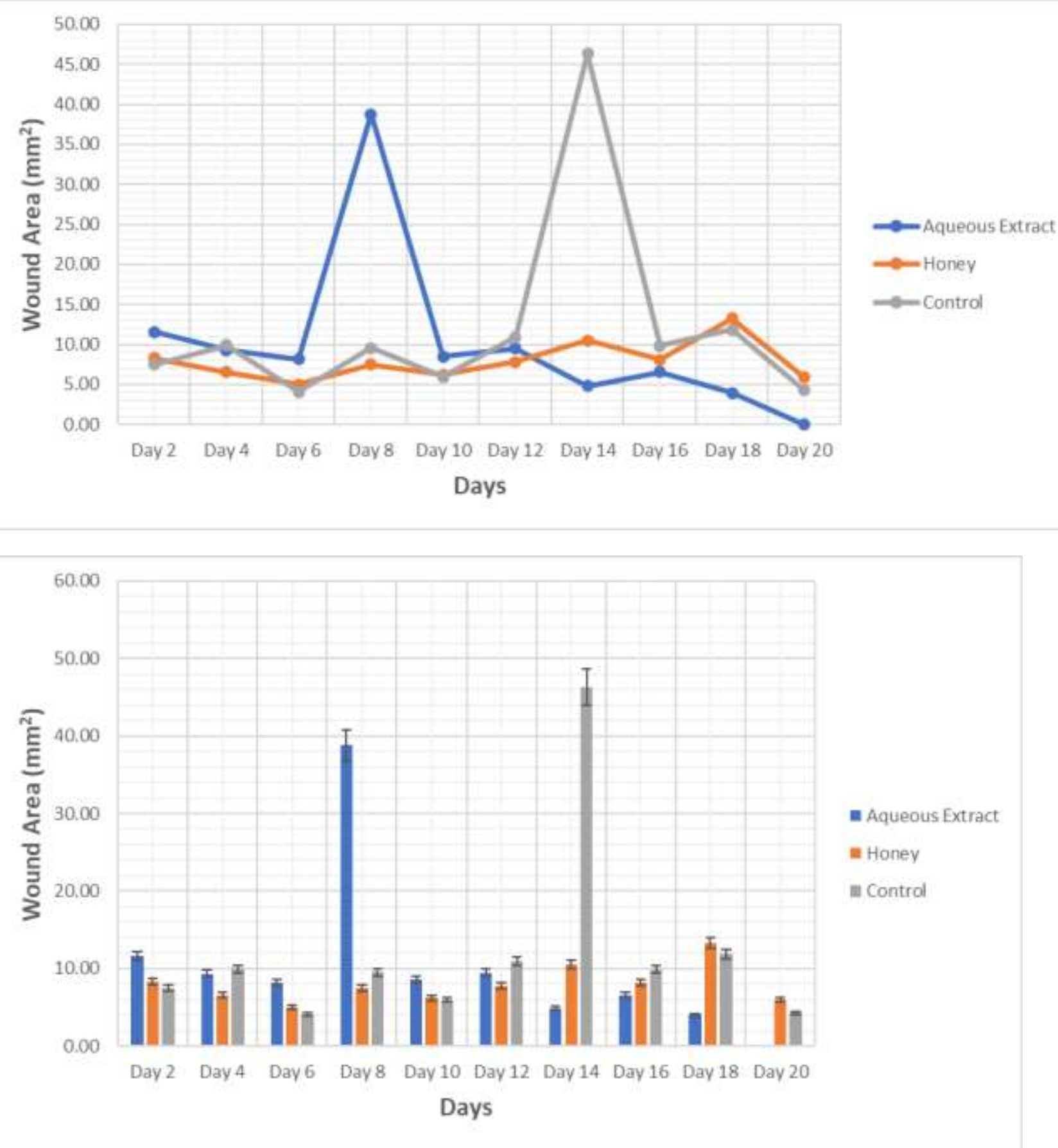

\section{REFERENCES}

1. Doupis J, Veves A. Classification, diagnosis and treatment of diabetic foot ulcers wound: A compendium of clinical research and practice, 2008, 20(5): 117-26.

2. Armstrong et al. Validation of a diabetic wound classification: Contribution of depth, infection and ischaemia to risk of amputation. Diabetes Care, 1998; 21: 855. pmid:9589255.

3. Pickwell et al. Eurodale consortium. Diabetic foot disease. Impact of ulcer location on ulcer healing: Diabetes Metab. Rev. 2013; 29: 377-383. pmid: 23390115 CrossRef Pubmed Google Scholar.

4. Ramsey, S. D. et al. Incidence, outcomes and cost of foot ulcers in patients with diabetes. Diabetes Care, 1999; 22: 382-387 pmid: 10097914 Abstract Google Scholar.

5. Boulton, R. J. M. et al. Diagnosis and management of diabetic foot complications. Arlington, VA: American

Diabetes

Association,

2018.

Professional diabetes.org/site/ 
professional.diabetes.org/sites/media/foot_complications_monograph.pdf.published 2018. Accessed June 25, 2021.

6. Kirsner, RS. et al. Expert recommendations for optimizing outcomes utilizing apligraf for diabetic foot ulcers. Podiatry Today. Websitepodiatrytoday.com/file /pT_orgo.pdf.published 2012. Accessed 25 June, 2021.

7. Vaves, A. et al. Apligraf Diabetic Foot Ulcer Study. Graftskin, a human skin equivalent, is effective in the management of non-infected neuropathic diabetic foot ulcers. A prospective randomized multicentre clinical trial. Diabetes Care, 2001; 24(2): 290-295.

8. Rupesh Thokur et al. Practices in wound healing studies in plants. Evidence-based complementary and alternative medicine. 2011/ArticleID4380561.

9. Handa, S.S. An overview of extraction techniques for medicinal and aromatic plants, in Extraction Technologies for Medicinal and Aromatic Plants. S. S. Handa, S. P. S. Khanuja, G. Longo and D. D. Rakesh, Eds., pp. 21-5, ICS-UNIDO. Trieste, Italy, 2008, view at: Google Scholar.

10. Shetty, S. et al. Evaluation of antioxidant and wound healing effect of alcoholic and aqueous extract of Ocimum sanctum Linn in rats. Evidence-based complementary and alternative medicine, vol. 5, no. 1, pp. 90-101, 2008.

11. Nayak, S. B. et al. Experimental evaluation of ethanolic extract of Carapa guianensis L. for its wound healing activity using three wound models. Evidence-Based complementary and alternative medicine, vol. 2011, Article ID 419612, 2011, view at: Publisher site/Google Scholar.

12. Esimone, C. O. Cutaneous wound healing activity of a herbal ointment containing leaf extract of Jatropha curcas L. (Eurphorbiaceae. International Journal of Applied Research in Natural Products, vol. 1, no. 4pp. 1-4, 2009, view at: Google Scholar.

13. Aladesanmie, J. A. Tetrapleura tetraptera molluscidal activity and chemical constituents. African Journal of Traditional Complementary Altern. Med., 491): 23-36 (Pubmed).

14. Ojewole, J. A., Adewunmi, C. O. Antiinflammatory and hypoglycaemic effect of T. tetraptera fruits aqueous extract in rats. J. Ethnopharmacol. 95 (2-3): 177-182.

15. Ajayi, O. B. et al. Effects of Tetrapleura tetraptera leaf extracts on plasma lipid profil and enzyme activities in some tissues of hyperciholesterolacmic rats. J. Nat. Prod. Plant Resour. 1:47-55.

16. Adewunmi, C. O. Plant molluscides: Potential of aridan from T. tetraptera fruits for schistosomiasis control in Nigeria. The science of total environment, 103: 21-23.

17. Ekwerenye, U. N., Okerie, C. F. Antibacterial activity of T. tetraptera (TAUB). Prod extracts. Int. J. Pharm. Bio. Sci. 1:734-41.

18. Abaoba, O. O. et al. Antimicrobial activities of some Nigerian spices on some pathogens. Agric. Bio. J. Worth Ans. 2:1187-93.

19. Aderibigbe, A. O. et al. anticonvulsant, analgesic and hypogycaemic effects of aridan isolated from T. tetraptera fruits in M. C. Journal of Biological Science, 7(80): 1520-1524.

20. Elizzi, A. et al. Inhibitory effects of saponins from T. tetraptera on luteinizing hormone release by pituitary cells. Plant Med. 56: 357-359.

21. Aderibigbe, A. O. et al. anticonvulsant, analgesic and hypogycaemic effects of aridan isolated from T. tetraptera fruits in M. C. Journal of Biological Science, 7(80): 1520-1524.

22. Ojewole, J. A., Adewunmi, C. O. Antiinflammatory and hypoglycaemic effect of T. tetraptera fruits aqueous extract in rats. J. Ethnopharmacol. 95 (2-3): 177-182.

23. Nwanu, J. A., Akah, P. A. Anticonvulsant activity of the volatile oil from the fruits of T. tetraptera. $J$. Ethnopharmcol. 18: 103-107.

24. Okwu, D. E. Identification of the key aroma compounds in dried fruits of X. aethiopica. Perspective on new crops and new uses. ASHS Press. Janick ed. 474-478.

25. Amoo, S. O. et al. Allelopathic potential of T. tetraptera leaf extracts on early seeding of five agricultural crops. South African Journal Botany, 74(1): 149-152.

26. David, E. T. Topically applied T. tetraptera stem-bark extract promotes healing of excision and incision wounds. Journal Intercult. Ethno-Pharmacol. 2014, 3(2): 63-67.

27. Otimanam, H. E. et al. Cutaneous wound healing activity of herbal ointment containing Tetrapleura tetraptera fruit extract. Nigerian Journal of Pharmaceutical and Applied Science Research, 9(2):1-7, 2020 (ISSN 1485-8059.

28. Shind, A. N. et al. The effects of carica papaya Linn latex in the healing of burn wounds in rats. Malaysian Journal of Medicine and Health Sciences, 3(2): 39-47.

29. Bhat, R. S. et al. Formulation and evaluation of polyherbal wound treatment. Asian Journal of Pharmaceutical Sciences, 2(1): 11-17.

30. Asif, A. et al. Wound healing activity of root extracts Berberis Iyceum role in rats. Phytotherapy Research, 21: 589-591. View at publisher, view at google scholar, view at Scopus. 
31. Gurung, S., Skalko-Basnet. Wound healing properties of carica papaya latex: In vivo evaluation of mice wound model. Journal of Ethno-Pharmacology, 121 (2): 338-341. View at Publisher, view at Google Scholar, view at Scopus.

32. Salcido, R. Fruits, berries and nuts: Phytochemicals in wound healing. Journal of Advances in Skin and Wound Care, 2014; 27(7): 296.

33. Budovsky, A. et al. Effects of medicinal plants on wound healing. Journal of Wound Repair and Regneration, 2015.

34. Odimegwu, D. C. et al. Wound healing and antibacterial activities of the extract of Dissotis theifolia (melasto-mataceae) stem formulated in a simple ointment bark. Journal of Medicinal Plants Research, vol. 2, no. 1, pp. 11-16, 2008. View at: Google Scholar.

35. Okoli, P. A. et al. Potentials of leaves of Aspilia atricana (compositae) in wound care: An experimental evaluation. BMC Complementary and Alternative Medicine, vol. 7, article 24, 2007. 